\title{
Structural characterisation of spintronic GaMnAs and GaMnN heterostructures grown by molecular beam epitaxy
}

\author{
M W Fay, Y Han, S V Novikov, K W Edmonds, K Wang, B L Gallagher, R P Campion, \\ C T Foxon and P D Brown
}

School of Mechanical, Materials and Manufacturing Engineering and School of Physics \& Astronomy, University of Nottingham, University Park, Nottingham NG7 2RD

\begin{abstract}
Observations of orthogonal orientations demonstrate the development of banded contrast features on inclined $\{\overline{1} \overline{1} \overline{1}\}_{\mathrm{B}}$ planes for the [110] projection within micron thick samples, attributed to a compositional fluctuation in the Mn content. The relationship of Mn content and layer critical thickness for the onset of precipitate and stacking fault formation is investigated. The formation of a Mn-O layer at the surface of the samples is also observed. The growth of $\mathrm{GaMnN} /(001) \mathrm{GaAs}$ heterostructures with and without AlN/GaN buffer layers is also compared. Layers without buffer layers show MnAs inclusions into the GaAs, with a reduced Mn content of the GaMnN layer significantly below the nominal composition. The use of AlN/GaN buffer layers is found to greatly reduce the density of these MnAs inclusions, retaining a higher proportion of the Mn within the epilayer.
\end{abstract}

\section{INTRODUCTION}

Ferromagnetic semiconductors raise the possibility of spintronic devices that combine both electronic and magnetic properties (Ohno 1998). Theoretically, ferromagnetism at room temperatures is achievable within GaMnAs and GaMnN for very high Mn concentrations (Dietl et al 2000), and this in principle can be achieved under non-stoichiometric growth conditions using molecular beam epitaxy (MBE). However, the development of these systems is limited by the low solubility of Mn in GaAs and $\mathrm{GaN}$ and the defect microstructure formed, comprising both point and extended structural defects.

\section{EXPERIMENTAL DETAILS}

Thin $(50 \mathrm{~nm})$ and thick $(1 \mu \mathrm{m}) \mathrm{Ga}_{1-\mathrm{x}} \mathrm{Mn}_{\mathrm{x}}$ As epitaxial layers with a SIMS determined $\mathrm{Mn}$ composition of either $2.2,5.6$ or 9 at $\%$ were grown at temperatures of 255,210 or $185^{\circ} \mathrm{C}$, respectively, on (001) oriented semi-insulating GaAs substrates, using $\mathrm{As}_{2}$ to reduce the concentration of As antisite defects (Campion et al 2003). Buffer layers of $100 \mathrm{~nm}$ thick, high temperature $\left(580^{\circ} \mathrm{C}\right) \mathrm{GaAs}$ followed by $50 \mathrm{~nm}$ thick, growth temperature GaAs provided template material for $\mathrm{Ga}_{1-\mathrm{x}} \mathrm{Mn}_{\mathrm{x}} \mathrm{As}$ growth. Magnetic measurements of these samples confirmed strong anisotropic ferromagnetism of these $\mathrm{Ga}_{1-\mathrm{x}} \mathrm{Mn}_{\mathrm{x}}$ As layers with the easy and hard directions of magnetisation corresponding to the [1 $\overline{1} 0]$ and [110] directions, respectively (Sawicki et al 2005). $\mathrm{Ga}_{1-\mathrm{x}} \mathrm{Mn}_{\mathrm{x}} \mathrm{N}$ layers with a target thickness of $0.3 \mu \mathrm{m}$ and $\mathrm{Mn}$ content ranging from $0.04 \%$ to $6.6 \mathrm{at} \%$ were grown at $680^{\circ} \mathrm{C}$ using plasma assisted-MBE on semi-insulating (001) GaAs (Novikov et al 2005). Samples grown on $0.15 \mu \mathrm{m}$ thick GaAs buffer layers were compared with samples grown on AlN/GaN/GaAs (each $0.15 \mu \mathrm{m}$ in thickness) buffer layers.

Electron transparent specimens prepared in plan view and cross sectional geometry using sequential mechanical polishing, dimpling and argon ion beam milling were assessed using conventional diffraction contrast techniques. Information on the chemical distributions in the layers was obtained using energy dispersive x-ray (EDX) analysis, electron energy loss spectroscopy (EELS) 


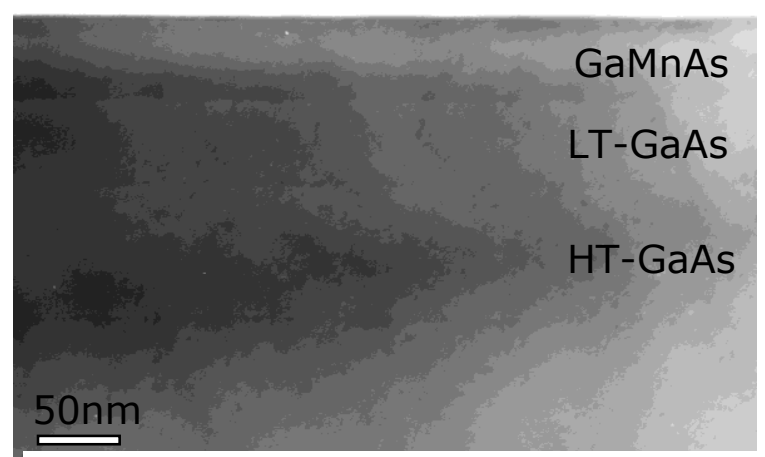

Fig. $1<110>$ many beam bright field TEM image of a defect free $50 \mathrm{~nm}$ thick $\mathrm{Ga}_{0.944} \mathrm{Mn}_{0.056} \mathrm{As} /(001) \mathrm{GaAs}$ epilayer.

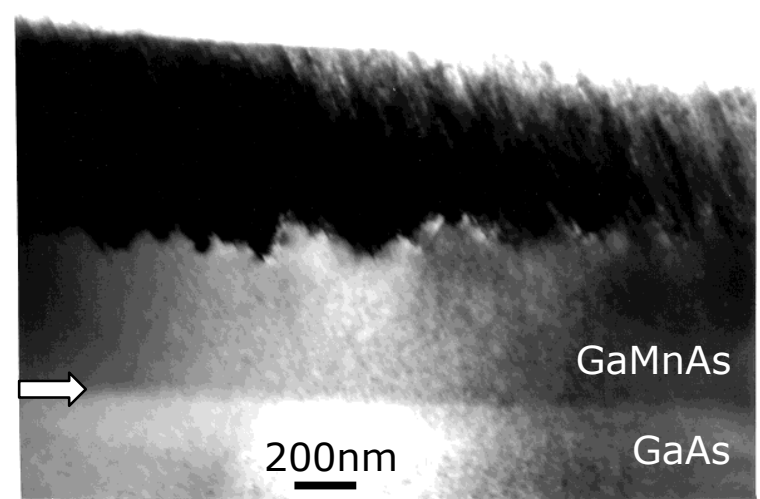

Fig. $3<110>$ many beam bright field TEM image of a $1 \mu \mathrm{m}$ thick $\mathrm{Ga}_{0.91} \mathrm{Mn}_{0.09}$ As layer.

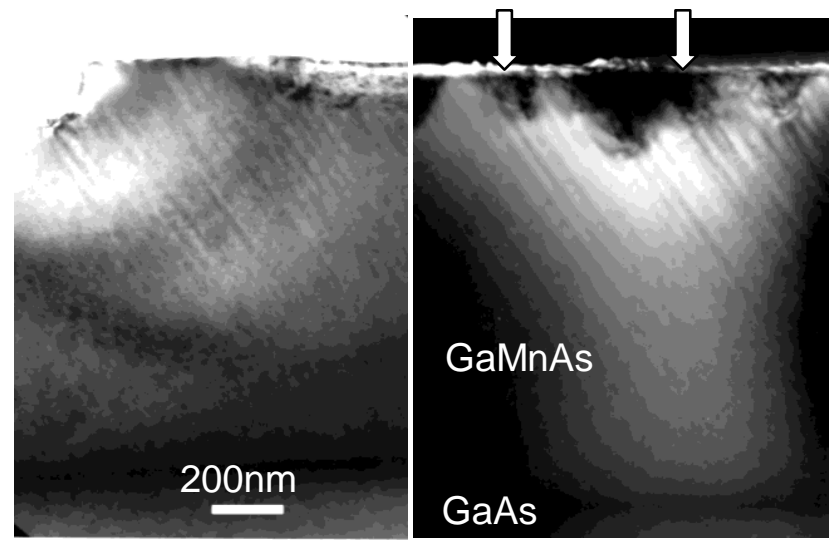

Fig. 2 (a) Bright field TEM image of a $1 \mu \mathrm{m}$ thick $\mathrm{Ga}_{0.944} \mathrm{Mn}_{0.056}$ As layer tilted slightly off the [110] projection. A domain structure and contrast reminiscent of ordering is apparent on $\{\overline{1} \overline{1} \overline{1}\}_{\mathrm{B}}$ planes.

(b) Dark field TEM image of a $1 \mu \mathrm{m}$ thick $\mathrm{Ga}_{0.95} \mathrm{Mn}_{0.05} \mathrm{As}$ layer tilted slightly off the [110] projection.

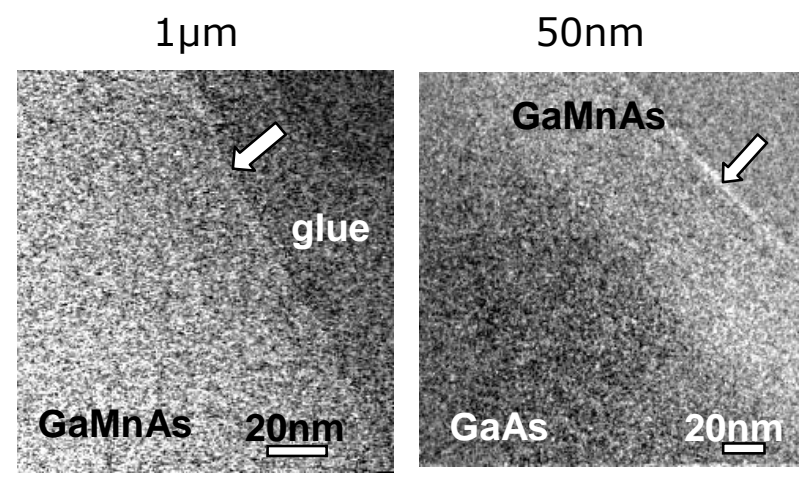

Fig. $4 \mathrm{Mn}$ sensitive EFTEM images from the surface of a $1 \mu \mathrm{m}$ thick $\mathrm{Ga}_{0.944} \mathrm{Mn}_{0.056}$ As layer and a 50nm thick annealed $\mathrm{Ga}_{0.91} \mathrm{Mn}_{0.09}$ As layer.

and energy filtered TEM (EFTEM) techniques using Jeol 2000fx and 4000fx instruments. The absolute crystal polarity of TEM sample foils was established using convergent beam electron diffraction (Ishizuka and Taftø 1984).

\section{RESULTS AND DISCUSSION}

50nm and $1 \mu \mathrm{m}$ thick $\mathrm{Ga}_{0.978} \mathrm{Mn}_{0.022}$ As epilayers showed no extended structural defects. Thin 50nm layers of $\mathrm{Ga}_{0.944} \mathrm{Mn}_{0.056}$ As similarly showed no extended defects, as shown in fig. 1. In contrast, $1 \mu \mathrm{m}$ thick $\mathrm{Ga}_{0.944} \mathrm{Mn}_{0.056}$ As epilayers exhibited domains of highly faulted twin structures at the layer surface (Fig. 2, black regions arrowed) and an irregular growth surface on the scale of 10 to $20 \mathrm{~nm}$. Of particular interest, a faint banded structure on one set of inclined advancing $\{\overline{1} \overline{1} \overline{1}\} \mathrm{B}$ planes, reminiscent of ordering, was visible in the [110] projection, corresponding to the direction of hard magnetisation, accentuated close to the $1 / 2(115)$ diffraction condition. However, it is noted that additional spots due to ordering were not discernible in selected area diffraction patterns due to the large spacing and diffuse nature of these banded features. This banded contrast became stronger further away from the $\mathrm{Ga}_{1-\mathrm{x}} \mathrm{Mn}_{\mathrm{x}} \mathrm{As} / \mathrm{GaAs}$ interface, although there was a perception of faint contrast at the original $\mathrm{Ga}_{1-\mathrm{x}} \mathrm{Mn}_{\mathrm{x}} \mathrm{As} / \mathrm{GaAs}$ interface as a point of origin. This banded contrast was not observed within any thin $50 \mathrm{~nm}$ layers, and hence is tentatively attributed to a modulated composition fluctuation becoming accentuated during growth due to accumulating epilayer strain. 
A marked effect on the development of the defect microstructure was observed by increasing the Mn concentration further. 5-10nm sized precipitates and surface stacking faults were observed within thin $50 \mathrm{~nm} \mathrm{Ga} \mathrm{Ga}_{0.91} \mathrm{Mn}_{0.09}$ As layers, while the corresponding $1 \mu \mathrm{m}$ thick $\mathrm{Ga}_{0.91} \mathrm{Mn}_{0.09} \mathrm{As}_{\text {samples showed }}$ an abrupt transition from defect free growth to a band comprising a high density of stacking faults preferentially aligned on one set of inclined $\{111\}$ planes, commencing $\sim 500 \mathrm{~nm}$ from the $\mathrm{Ga}_{1-\mathrm{x}} \mathrm{Mn}_{\mathrm{x}} \mathrm{As} / \mathrm{GaAs}$ interface (fig 3). Precipitates, tentatively attributed to MnAs, were observed at the onset of the stacking faults.

Elementally sensitive maps obtained from both the $50 \mathrm{~nm}$ and $1 \mu \mathrm{m}$ thick layers indicated a relatively uniform distribution of $\mathrm{Mn}$ throughout all $\mathrm{Ga}_{1-\mathrm{x}} \mathrm{Mn}_{\mathrm{x}} \mathrm{As}$ samples, with a peak in the $\mathrm{Mn}$ content at the layer surface of both samples (arrowed in Fig. 4). This Mn layer was associated with a strong $\mathrm{O}$ signal. The perception of a Mn-O layer at the surface suggests the oxidation of a surface $\mathrm{Mn}$ layer, consistent with recent X-ray absorption studies (Edmonds et al 2004). This indicates that Mn is acting as a surfactant, with segregation of $\mathrm{Mn}$ at the growth surface in response to the build up of misfit strain.

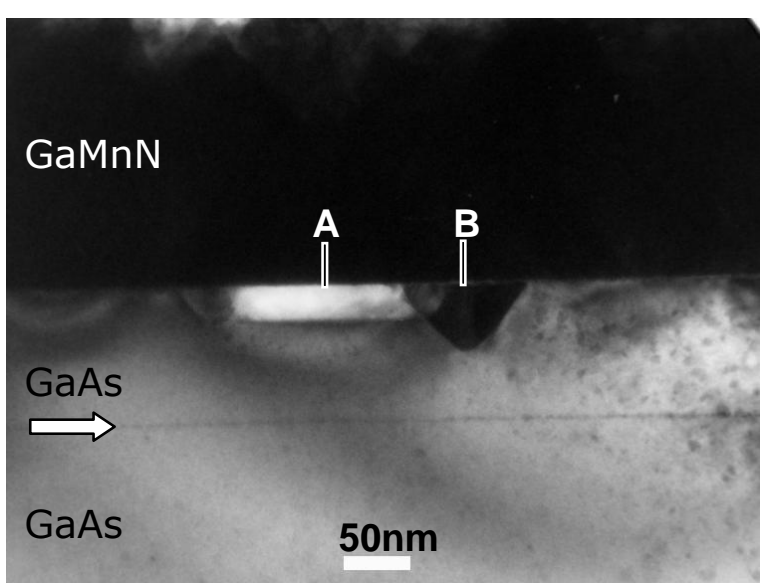

Hall-effect measurements unambiguously showed that the $\mathrm{Ga}_{1-\mathrm{x}} \mathrm{Mn}_{\mathrm{x}} \mathrm{N}$ samples had strong p-type conductivity. Figure 5 presents a $<110>$ cross sectional TEM image of a $\mathrm{Ga}_{0.97} \mathrm{Mn}_{0.03} \mathrm{~N} / \mathrm{GaAs}(001)$ sample. This image is typical of all the $\mathrm{Ga}_{1-\mathrm{x}} \mathrm{Mn}_{\mathrm{x}} \mathrm{N} / \mathrm{GaAs}(001)$ samples investigated with a line of voids at the nitride/GaAs interface, and intriguingly a high density of inclusions extending into the GaAs buffer layer. It is suggested that the line of voids are due to preferential milling of localised strain centres at the interface, although some cooperative voiding mechanism associated with the formation of inclusions remains a possibility (Tricker et al

Fig $5<110>$ many beam bright field TEM image of $\mathrm{Ga}_{0.97} \mathrm{Mn}_{0.03} \mathrm{~N} / \mathrm{GaAs}(001)$ showing (A) a void and (B) an inclusion at the interface. 1998). The line of the original GaAs/GaAs interface is also perceived, presumably delineated by a remnant oxide layer (Fig.5 arrowed). EELS analysis revealed the inclusions to be rich in $\mathrm{Mn}$, with no significant edges corresponding to $\mathrm{N}$ or $\mathrm{O}$ being detectable (Fig 6a). Complementary EDX spectra from both cross sectional and plan view samples confirmed the presence of high levels of As as well as Mn within such inclusions, also showing a deficiency of $\mathrm{Ga}$ as compared with the surrounding GaAs matrix (Fig. 6b). Associated diffraction patterns confirmed that such inclusions adopted a hexagonal structure, with a and c lattice parameter spacings of 3.72 and $5.69 \AA$, respectively, consistent with the formation of $\alpha$-MnAs (ASM 1992). It is considered that such MnAs inclusions develop during growth, due to the limited solid solubility of $\mathrm{Mn}$ in $\mathrm{Ga}_{1-\mathrm{x}} \mathrm{Mn}_{\mathrm{x}} \mathrm{N}$ for the growth conditions used, with the displacement of $\mathrm{Ga}$ from the GaAs substrate through a process of differential cross diffusion. Although MnAs is a ferromagnetic metal with a $\mathrm{T}_{\mathrm{c}}$ of around $313 \mathrm{~K}$, similar properties are observed for the layers grown with and without
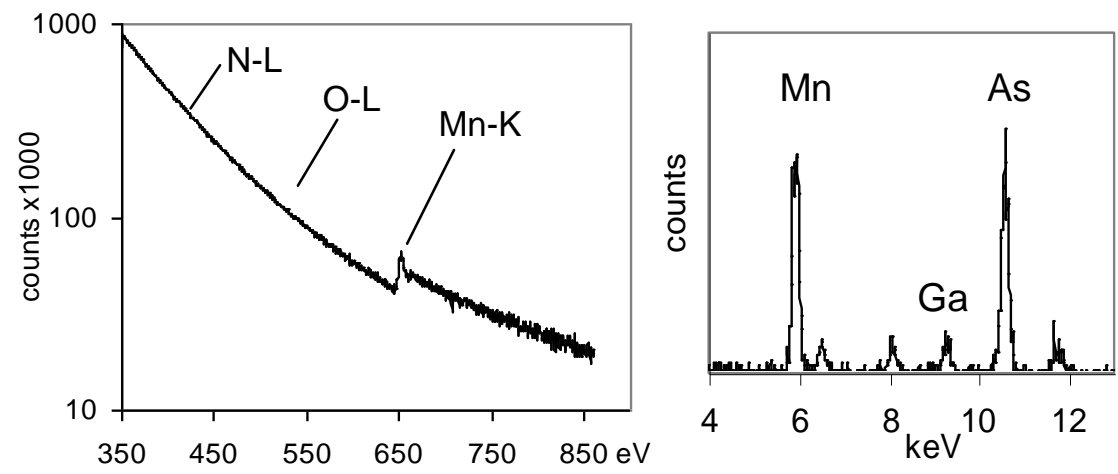

Fig. 6 a) EELS and b) EDX spectra obtained from an inclusion viewed in cross section, confirming the material to be MnAs. 


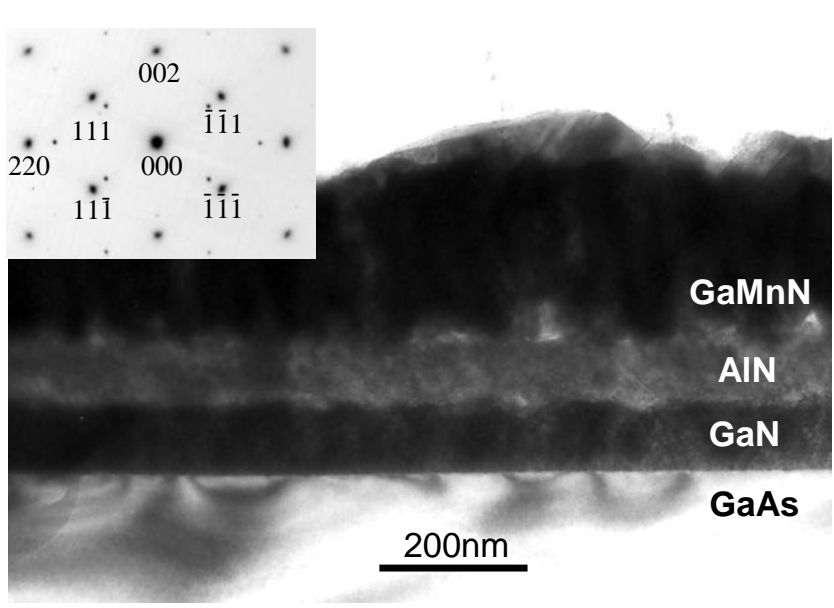

Fig. $7<110>$ many beam bright field TEM image of a $\mathrm{Ga}_{0.982} \mathrm{Mn}_{0.018} \mathrm{~N} / \mathrm{AlN} / \mathrm{GaN} / \mathrm{GaAs} / \mathrm{GaAs}(001)$ epilayer with associated diffraction pattern inset.

AlN buffer layers, suggesting that the inclusions do not make a significant contribution to the electrical properties in the layers investigated here. Transport properties will not be affected as the inclusions are not continuous.

Figure 7 shows a $\langle 110\rangle$ many beam cross sectional TEM image of a $\mathrm{Ga}_{0.982} \mathrm{Mn}_{0.018} \mathrm{~N} / \mathrm{AlN} / \mathrm{GaN} / \mathrm{GaAs}$ (001) epilayer. A continuous zincblende AlN layer can be seen with a relatively abrupt interface. Although the AlN layer exhibited rotated columnar grains, the $\mathrm{Ga}_{1-\mathrm{x}} \mathrm{Mn}_{\mathrm{x}} \mathrm{N}$ layer was again found to be single crystal cubic, albeit highly faulted with a fine subgrained structure on the scale of $\sim 100 \mathrm{~nm}$. Notably, such AlN/GaN buffer layers were found to be largely effective in suppressing the formation of MnAs inclusions into the GaAs. Accordingly, the use of AlN/GaN buffer layers has implications for the control of $\mathrm{Mn}$ content, alloy uniformity and the p-type behaviour of $\mathrm{Ga}_{1-\mathrm{x}} \mathrm{Mn}_{\mathrm{x}} \mathrm{N}$ epilayers grown by PA-MBE.

\section{SUMMARY}

The microstructure of $\mathrm{Ga}_{1-\mathrm{x}} \mathrm{Mn}_{\mathrm{x}}$ As layers is strongly dependent on the layer thickness. Since thin and thick layers of nominally the same composition exhibit such different microstructures, caution is required when applying the results for thick layers from other characterisation techniques to explain the functional properties of thinner layers. The high levels of faulting associated with the $1 \mu \mathrm{m}$ thick $\mathrm{Ga}_{0.944} \mathrm{Mn}_{0.056} \mathrm{As}$ and $\mathrm{Ga}_{0.91} \mathrm{Mn}_{0.09}$ As samples is considered to be a response to the development of misfit strain.

Strongly p-type zincblende $\mathrm{Ga}_{1-\mathrm{x}} \mathrm{Mn}_{\mathrm{x}} \mathrm{N}$ epilayers grown by PAMBE show $\alpha$-MnAs inclusions at the $\mathrm{Ga}_{1-\mathrm{x}} \mathrm{Mn}_{\mathrm{x}} \mathrm{N} / \mathrm{GaAs}(001)$ interface extending into the GaAs buffer layer. The use of AlN/GaN buffer layers was found to be effective at suppressing the formation of such inclusions.

\section{ACKNOWLEDGEMENTS}

The authors would like to acknowledge the contributions of B. Ja. Ber and A.P.Kovarsky for the SIMS studies. This work was supported under EPSRC contract GR/S25630/01 and GR.S81407/01

\section{REFERENCES}

Alloy phase diagrams, ASM handbook, Volume 3, Metals Park, Ohio: American Society for Metals International, 1992.

Campion R P, Edmonds K W, Zhao L X, Wang K Y, Foxon C T, Gallagher B L and Staddon C R, 2003, J Cryst Growth 247, 42

Dietl T, Ohno H, Matsukara F, Cibert J and Ferrand D, 2000 Science 287, 1019

Edmonds K W, Farley N R S, Campion R P, Foxon C T, Gallagher B L, Johal T K, Van der Laan G, MacKenzie M, Chapman J N and Arenholz E 2004, Appl. Phys. Lett. 844065

Ishizuka K and Taftø J, 1984 Acta Cryst. B40, 332-337

Kaminska E, Piotrowska A, Dietl T, Gallagher B L, cond-mat/0410544, Phys. Rev. B (in press)

Novikov S V, Edmonds K W, Zhao L X, Giddings A D, Wang K Y, Campion R P, Staddon C R, Fay M W, Han Y, Brown P D and Sawicki M, J Vac Sci and Tech B in press

Ohno H 1998 Science, 281, 95

Sawicki M, Wang K Y, Edmonds K W, Campion R P, Staddon C R, Farley N R S, Foxon C T, Papis E, Tricker D M, Brown P D, Cheng T S, Foxon C T and Humphreys C J 1998 , Applied Surface Science 123/124 22 